\title{
TRTaKadeMi
}

ISSN 2149-9446 | Cilt 06 | Sayı 12 | Mayıs 2021 | Dijital Hayat ve Etik

\section{Dijitalleşme, Psikopolitika, Neoliberalizm ve İktidar Teknikleri}

Psikopolitika: Neoliberalizm ve Yeni Iktidar Teknikleri

Byung-Chul Han (2020), Türkçeye Çeviren: Haluk Barışcan

3. baskı, ìstanbul: Metis Yayınları, 104 sayfa

ISBN-13: 978-605-316-170-7

\section{Abuzer YEŞiL*}

\section{Giriş}

Kapitalizm, iktidar ve birey ilişkisi daha çok emek sömürüsü bağlamında tartışımıştır. Ağırlıklı olarak Marksist paradigma etrafinda şekillenen eleştirel yaklaşımlar bu indirgemecilik sebebiyle "insan" tarafinı izah etmekte eksik kalmışlardır. Küreselleşme ile birlikte kapitalizmin bir kabuk değişimi yaşaması iktidar ve sömürü biçimlerinde bir dönüşüme neden olmuştur. Bu neoliberal dönemde meta dışı üretim ön plana çıkmış, enformasyon başat bir konum edinmiştir. Dolayısıyla yeni tahakküm süreçleri enformasyon etrafinda şekillenmiştir. Orta Çă̆'da bilginin kilisenin tekelinde olmasına benzer bir durum ortaya çıkmıştır ancak önemli bir farkla. Artık insan, sistemin karşısında değil içindedir. Bilgi insandan uzak tutulmamakta, insan bilgiye boğulmaktadır. Öyle ki neyin hakikat olduğunu tespit edemeyecek kadar enformasyona ulaş(tırıl)maktadır. Bu durum neoliberal iktidar tekniklerinin çözümlenmesini alabildiğine zorlaştırmaktadır. Tam bu noktada Güney Koreli Yazar Byung-Chul Han, neoliberal kapitalizmin iktidar tekniklerine ışık tutmaktadır.

\section{Byung-Chul Han ve Psikopolitika}

Bir felsefeci ve kültür kuramcısı olan Han, 1959'da Seul'de doğmuş, 1980'li yıllarda Almanya'ya yerleşmiştir. Doktorasını Almanya'da yapan, ardından çeşitli üniversitelerde akademik çalışmalar yapan yazar 2012 yılından bu yana Berlin Sanat Üniversitesinde ders vermektedir. Akademik hayatının ilk dönemlerinde felsefe, 
Alman edebiyat ve katolik teolojisine yoğunlaşan yazar, ilerleyen dönemlerde on sekiz, on dokuz ve yirminci yüzyıl felsefesi, etik, fenomenoloji, kültür kuramı, estetik, din, medya kuramı ve kültürlerarası felsefe gibi konulara yönelmiştir. Eserlerini Almanca yazan Han'ın 2021 Nisan itibariyle 16 kitabı bulunmaktadır. Bunlardan dokuzunun son iki yıl gibi kısa bir sürede Türkçe basılması yazarın değerinin Türkiye'de fark edildiğine işaret olarak değerlendirilebilir. Türkçeye çevrilen kitapları: Yorgunluk Toplumu, Şeffaflık Toplumu, Eros'un Istırabı, Şiddetin Topolojisi, İktidar Nedir?, Güzeli Kurtarmak, Zamanın Kokusu, Kapitalizm ve Ölüm Dürtüsü ve Psikopolitika'dır. Psikopolitika, Haluk Barışcan tarafindan Almancadan Türkçeye çevrilmiştir.

Byung-Chul Han, kitabın amacını doğrudan vurgulamamıştır. Ancak kitabın amacının neoliberal kapitalist iktidar tekniklerinin insana tahakküm biçimleri ve insanın bunun karşısındaki durumunu ortaya koymak olduğu görülmektedir. Yazar, kapitalizmin yaşamsal sürecinde kendi iktidar tekniklerinin dönüştüğünü iddia etmekte ve güncel hâlini psikopolitika olarak tanımlamaktadır. Yazarın tanımlamasının küreselleşme sonrası enformasyon kapitalizmi dönemine karşılık geldiği anlaşılmaktadır. On üç bölümden oluşan kitapta yazar neoliberalizmin insanın özgürlük, anlam, duygu, heyecan, mahremiyet, eğlence gibi farklı yönlerine dönük nüfuzunu irdelemekte ve bunların kapitalist iktidar tarafindan nasıl araçsallaştırılarak kullanıldığına dair analizler yapmaktadır. Yazar, başka teorileri daha çok tartışmak maksadıyla kullanmakta, doğrudan bir teoriye dayanmamaktadır. Kitapta yazarın hissiyatının yansımalarını da görmek mümkündür. Bölüm girişleri her defasında yeni bir konuya giriyormuş izlenimi verse de devamında kitabın ana ekseni kendini göstermektedir. Yazarın anlatılarında bir iç tutarlılık olmakla beraber bunu tespit etmek biraz okuyucuya kalmaktadır.

Özgürlüğün Krizi başlıklı ilk bölüm insanın özgürlüğü sorunsalına yoğunlaşmakta ve neoliberal kapitalizm bağlamında tartışmaktadır. Han, günümüz insanının özne değil özgür, sürekli kendini tasarlama ve yeniden icat etme çabasında olan bir proje olduğunu düşünmektedir. Birey, dışsal baskıya değil idealize edilmiş içsel baskıya (performans ve mükemmelleşme baskısı) teslim olmaktadır ve bir performans öznesine dönüşmektedir. Projeksiyonunu neoliberal kapitalizme kaydıran Han, bu sistemin özgürlüklere engel olup kontrol etmeye çalışan değil, aksine özgürlüğü yayarak sömüren zekice bir sistem olduğunu dile getirmektedir. Öyle ki özgürlüğün dışa vurulmasında önemli işlevi olan heyecan, oyun ve iletişim gibi pratiklerin tamamını sömürür ve maksimum kazanca erişir. Yazara göre üretici güçler ile üretim ilişkileri arasındaki çelişkinin komünist devrimle ortadan kaldırılması mümkün değildir çünkü kapitalizm kendisini bizzat dönüştürerek mevcut koşulların ötesine 
geçer. Braudel'e (2020) göre de kapitalizm konjonktürel bir karaktere sahiptir ve kolaylıkla kendini uyarlayıp dönüşebilmesi onun güçlü özelliklerindendir (s.58-62). Han’a göre işçi, girişimciye dönüşmüştür ve sınıf ayrımı bizzat kapitalizm tarafindan ortadan kaldırılmıştır. Yeni düzen bütün 'sınıflar'ı enterne etmiş ve sömürüyü bir öz sömürüye dönüştürmüştür. Dolayısıyla sömürülenin ortadan kaldıracağı bir sömüren kalmamıştır. Konuyu dijital çağla ilişkilendiren yazar, özgürlük ve iletişimin topyekûn bir kontrol ve gözetime dönüştüğünü, sosyal medyanın panoptikon hâline geldiğini dile getirmektedir. Bu dijital panoptikonun, Bentham'ın bireyleri birbirinden yalıtan panoptikonundan farkı; sakinlerinin yoğun iletişimine izin vermesi, kendi istekleriyle her şeylerini ifşa etmelerini ve bu şekilde gözetleyenle iş birliğine girmelerini sağlamasıdır. Dijital panoptikon, şeffaflık talep etmekte ve bunu da enformasyon özgürlüğü adına yapmaktadır. Gerçekte ise her şeyin hızlıca enformasyon kanalı üzerinden sisteme aktarılması ve ekonomik çıktılara dönüştürülmesi söz konusudur. Bu yaklaşımını Şeffaflık Toplumu'nda da vurgulayan Han’a göre (2020) şeffaflık bu şekilde topyekûn uyumu doğurur. Big data aracılığıyla dijital psikopolitika çağına doğru gidilmektedir. Bu araçla elde edilen bilgi, insan ruhuna nüfuz etmeyi ve düşünce öncesi etkilemeyi mümkün kılan bir iktidar bilgisidir.

Kitabın ikinci bölümü Akıllı İktidar'da yazar, neoliberal iktidarın şiddete dayanmayan, özgürlüğe alan açan müsamahakâr bir iktidar olarak akıllı ve incelikli bir şekle büründüğünü ifade etmektedir. Bu iktidar bireyi karşısına almadığı aksine ona yanaştığı için görünür değildir, dolayısıyla özne kendi tabi oluşunun farkında değildir. Bu iktidar boyun eğdirme yerine bağımlılık yaratmayı, yasaklama yerine ayartmayı amaçlamaktadır. İktidarın mührü de "Like/Beğendim" simgesidir. Yazara göre neoliberalizm "Beğendim” kapitalizmidir (s.25).

Yazar, Köstebek ve Yılan başlıklı üçüncü bölümde biyopolitik ile psikopolitik iktidarlardaki insan tiplerini köstebek ve yılan metaforlarıyla değerlendirmektedir. Disiplin temelli biyopolitik iktidar; aile, okul, hapishane, kışla, hastane ve fabrika gibi mekânlarla işleyen kapalı bir sistemdir ve bu sistemdeki köstebek işçidir (s.27). Ancak endüstri sonrasının maddi olmayan ağ tarzı üretim şekilleri açıklık ve sınırsızlık gerektirmektedir ve köstebek buna uygun değildir. Yeni sembol yılandır ve girişimciye karşılık gelir. Illk tip rejim "beden" gibi organize olmuştur, ikincisi ise "ruh" gibi davranır ve psikopolitiktir. O yüzden motivasyon, proje, rekabet, optimizasyon ve inisiyatif gibi tahakküm teknikleri kullanır.

Han, Biyopolitika başlığında psikopolitika öncesi iktidarın yapısına değinmektedir. Michel Foucault'nun (2017) da üzerinde durduğu disiplin iktidarı endüstrileşmenin bir çıktısıdır. Disiplin iktidarı bireyi, eski tanrısal niteliğe sahip iktidar gibi ölümle korkutarak değil, disipline ederek bir makine gibi endüstrinin hizmetine koşmayı hedefler. 
Normlar, emirler ve yasaklar "normal”i belirler ve normdan her türlü sapmayı engeller. Disiplin iktidarı zihinsel olana da el atar ama henüz 'ruh’a yönelmemiştir.

Foucault'nun İkilemi kitabın beşinci bölümüdür. Han, bedenin tahakküm altına alınması ve sömürülmesi temeline dayanan biyopolitikaya yoğunlaşan Foucault'nun zamanla bunun neoliberal rejimi açıklamada yetersiz kaldığını fark ettiğini ancak yeni durumu tam anlayamadığını ifade etmektedir (s.34-35). Kapitalizmin bir beden politikasından psikopolitikaya dönüşü üretim biçimindeki dönüşümle ilgilidir. Artık şeyler değil, enformasyon ve program gibi şey olmayan varlıklar üretildiğinden neoliberal tahakkümün ekseni bedenden psişik ya da zihinsel süreçlere kaymıştır. Bernard Stigler'i eleştiren Han, onun psiko-iktidarın psikolojik tekniklerini salt televizyon üzerinden okumasını yanlış bulmuştur. Zira bu, dijital çağı izah etmekte yetersiz kalmaktadır (s.33-34).

Altıncı bölümde Öldürerek Tedavi başlığı kullanan yazar, neoliberal kapitalizmin kişisel gelişim adına bireyin kendini optimize etmesini teşvik ettiğine vurgu yapmaktadır. Birey bütün işlevsel zayıflıklarını tedavi konusu olarak algılamaktadır ve kendi verimliliğinin ölçülebilir olması onu motive etmektedir. "Kendini yönetme atölyeleri, yaşam koçları, motivasyon arttırıcı hafta sonları, yaşam koçları, kişilik geliştirme seminerleri ve zihin antrenmanları" (s.37) gibi teknikler bu amaca hizmet etmektedir. Bu sürekli optimizasyon çabası ruhu sömürür, zihinsel çöküşe yol açar, depresyona sebep olur ve kişiyi harap eder. Tedavi aslında bireyi öldürmektedir.

Yazar yedinci bölüme Şok başlığı atmıştır ve Naomi Klein'in (2010) Şok Stratejisi kitabındaki iki kahraman üzerinden iktidar tekniklerini tartş̧maya devam etmiştir. Kahramanlardan Dr. Cameron, ruhu şoklayarak tabula rasaya geri döndürebileceğini düşünmektedir ve vahşi insan deneyleri yapmaktadır. Friedman ise bu yolla toplumları "silmeyi", devlet müdahalesi, ticaret engelleri ve sabitlenmiş menfaatler gibi bozukluklardan arındırarak saf kapitalizme döndürmeyi hayal etmektedir. Han, bu tekniklerin disiplin iktidarına uygun ancak neoliberal iktidara uygun olmadığını düşünmektedir. Çünkü neoliberal iktidar olumsuzluğa değil olumluluğa, tehdide değil olumlu duygulara, acıya değil Like/Beğendim'e, şoka değil okşamaya, karşıtlığa değil ayartmaya, arzuları silmeye değil not almaya, baskıya değil hoşa gitmeye dayanır.

Dost Big Brother başlığıyla Han, gözetimi George Orwell'in 1984 romanıyla karşılaştırmalı olarak irdelemektedir. Romandaki kısıtlamaya dayalı kontrol günümüzde geçerliliğini yitirmiştir. Big Brother artık dosttur. Bu yanılsama sebebiyle gözetim çok verimli gerçekleşmektedir. Dijital panoptikon, Bentham'ın Big Brother'ından da farklıdır. Onun panoptikonu görünmez ise de sakinlerinin kafasında hep vardır. 
Ancak dijital panoptikonda kişilerin kafası rahattır, gözetlendiğinden habersizdir. Kendini özgür hissetmektedir. Bu yaklaşım Bauman'ın (2016) gözetim anlayışının da ötesine geçmektedir.

Dokuzuncu bölüm olan Heyecan Kapitalizmi'nde yazar duygu ile duygulanım ve heyecan arasında bir ayrım yapmaktadır. Duygu objektiftir, bir anlatya yer açan uzunluk ve genişliği vardır. Oysa duygulanım ya da heyecan öznel olup anlatılabilir değildir. Heyecan uçucu ve kısa sürelidir. Duygulanım ise anlıktır. Duygu edimsel olmadığından kapitalizm tarafindan kolay sömürülemez ancak heyecan dinamik, koşullara bağlı ve edimsel olduğundan heyecan kapitalizmi tarafindan sömürülür. Han, dijital ortamın bir duygulanım ortamı olduğunu, dijital iletişimin duygulanım boşalmasını kolaylaştırdığını ve salt zamansallığı dolayısıyla duygudan çok duygulanım naklettiğini söylemektedir. Heyecan, özgür öznelliğin ifadesi olarak neoliberal rejim tarafindan verim ve performansı arttırmak maksadıyla kaynak olarak kullanılmaktadır. Yazar bu yaklaşımıyla Eva Illouz'dan (2018) ayrılmakta ve ona eleştiriler getirmektedir.

Oyunlaştırma başlıklı onuncu bölümde Han oyun olgusunun heyecan, başarı, ödül, yavaş olmaması gibi özelliklerinin heyecan kapitalizmi tarafindan ele geçirildiğini, işin ve iletişimin oyunsallaştırıldığını vurgulamaktadır. Böylece oynayan insan tahakküme tabi olmuştur. Toplumsal iletişim de "beğendim", "arkadaş" ve "izleyen"lerle oyuna dönüşmüş ve ticarileştirilmiştir.

Big Data, kitabın en geniş bölümüdür. Big Data'nın etkin kontrole imkân tanıdığını söyleyen Han, dijital optiğin her açıdan gözetlemeyi mümkün kılarak ruha dahi ulaşabildiğini söylemektedir. David Brooks'un “Dataizm” kavramsallaştırmasına işaret eden yazar, bu kavramın ikinci bir Aydınlanma vurgusuyla ortaya çıktığını iddia etmektedir (s.64). Birinci Aydınlama'da istatistik merkezde iken ikinci Aydınlanma'da şeffaflık ön plandadır. "Her şey veri ve enformasyon olmalıdır" (s.65). Dataizm, dijital totalitarizme giden bir ideolojidir. Sezgiyi kenara iten sadece verilerle işleyen bilginin devridir. Dataizm her türlü anlamlı bağlamı ortadan kaldırmaktadır. Anlam gitmiş, veri gelmiştir. Hayatın ölçülebilir ve sayısal olarak ifade edilebilir olduğu inancı dijital çağa hâkimdir. Bu inançla bedensel ve zihinsel performans arttırılmaya çalışılır. Ancak insanın kendisinden toplanan bunca veri "Ben kimim?” sorusuna cevap vermez. Kendilik bir anlam ifade etmeyecek kadar parçalara ayrılmıştır. İnsan kendi verileriyle bir hakikate ulaşma amacında değildir. Kendini izleme durumu ahlak ve hakikatten arındırılmıştır. Mikro-hedefleme ile bireye özel bir psikopolitik tahakküm süreci işletilir. Han’a göre Big Data, insanın kendisinin bile farkında olmadığı bilinç dışı bireysel ve kolektif eylemlerini erişilebilir kılacak ve görünür hâle getirecektir (s.71-72). Yazar, insan hafizasının unutmayı zorunlu olarak barındıran bir 
anlatı olduğunu, buna karşılık dijital hafizanın olayların ve enformasyonun sayılıp birbirine eklenmesinden ibaret olup bir şey anlatmadığını dile getirmektedir. Han, Big Data'nın ölçülebilirlik ve sayısallaştırılabilirlik özellikleriyle mutlak bilgi izlenimi verdiğini ama aslında sadece şeyler arasındaki korelasyonlara dayandığını, ruhtan yoksun olduğunu ifade etmektedir. Bilgide nedensellik yerine korelasyon vardır. Kavram ve ruh bilginin dışına itilmiştir.

On ikinci bölümde Öznenin Ötesinde başlığını kullanan Han, neoliberal psikopolitikanın özneyi psikolojiden arındırdığını hatta boşalttığını ve böylece adı olmayan bir yaşam biçimi için serbest bıraktığını dile getirmiştir. Son bölüm Budalalık'ta filozofları ironik bir şekilde budala olarak tanımlayan Han, bunu mevcudun dışına çıkarak öteki olana ulaşmaya çalışmaları ve yeni bir şey söyleme zorluğuna talip olmalarıyla açıklar. Bugün ise budala kalmamış gibidir. Dijital ağın getirdiği uzlaşma zorlaması, budalalıkları bastırmaktadır. İletişimin farklı olanın direncine tahammülü yoktur, aynıların cehenneminde en yüksek hızına ulaşır. Budalalık tam bu noktada ağ dışı kalmayı, bağlantısız ve enformasyonsuz olmayı, uyum düzeninin dışında kalabilmeyi ifade eder. Sınırsız iletişime karşı olmak, susma, sessizlik ve yalnızlığın özgürlük alanlarını yaratmaktır. Her şeyi duyurmaya dayanan neoliberal tahakküme teslim olmamaktır. Bu, Han'ın tavsiye ettiği türden bir budalalıktır.

\section{Sonuç}

Byung-Chul Han'ın bu eseri neoliberal kapitalizmin insan için ürettiği sorunlara yoğunlaşmakta, özgürlüğünün kendi rızasıyla nasıl elinden alındığını göstermektedir. Ancak Han da çoğunlukla tespit ve eleştiri yapmakta, çözüme dair bir projeksiyon sunamamaktadır. Bu, insanın çaresizliğiyle baş başa kalması anlamına gelmektedir. Onun tespit ve eleştirilerini farklı kılan, insan olgusuna ruh, duygu, anlam penceresinden bakabilmesidir. Bu, kitabı güçlü kılan özelliklerinin başında gelmektedir. Bir diğer güçlü yanı, sosyal bilimler literatüründe çokça işlenen iktidar ve gözetim olgularını Bentham ve Foucault perspektifinin ötesine taşıyabilmesi ve yeni bir tartışma zemini oluşturabilmesidir. Yazar, kitabında geçmiş ve çağdaş dönemin düşünürlerine atıflara ilerlemektedir. Bazen onları referans almakta bazen de eleştirerek tartışmaya girmektedir. Bu düşünürlerin fikirlerini temel bir düzeyde de olsa bilmek Han'ı anlamak için faydalı olacaktır. Kitapta kavramsallaştırmaya dayalı derin bir üslup kullanıldığından anlaşılabilmesi için hem yavaş ve dikkatli bir okumaya hem de kitabın ana konusuna ilişkin literatüre aşina olmaya ihtiyaç vardır. Derin üslubuna rağmen kitabın hacminin büyük olmaması okuyucu için motive edici olabilir. Ayrıca bu konu ekseninde özellikle Türkçe literatürün zayıf olduğu söylenmelidir. Türkçe literatürde dijitalleşmeyle ilişkili eleştirel iktidar okumasının daha çok gözetim ve 
ekonomi temelli olduğu söylenebilir. Bu, kıymetli olmakla beraber bir indirgemeciliği kaçınılmaz kılmaktadır. Biraz da Batılı literatürden yoğun beslenmenin bir yansıması olarak değerlendirilebilecek bu durumu aşabilmek için ‘Enformasyon Çağı'na daha geniş bir bakış atmak ve insanın bu çağda maruz bırakıldığı anlamsızlığa çözüm olabilme duyarlıığını taşımak gerekmektedir. Yazarın perspektifi bu alanda yapılacak çalışmalara motivasyon kaynağı olacak kalitededir.

\section{Kaynakça}

Bauman, Z., \& Lyon, D. (2016). Akışkan Gözetim (2 b.). (E. Yılmaz, Çev.) İstanbul: Ayrıntı Yayınları.

Braudel, F. (2020). Kapitalizmin Kısa Tarihi. İstanbul: Say Yayınları.

Foucault, M. (2017). Cinselliğin Tarihi. (H. Uğur Tanrı̈ver, Çev.) İstanbul: Ayrıntı Yayınları. Han, B.-C. (2020). Şeffaflık Toplumu. (H. Barışcan, Çev.) İstanbul: Metis Yayınları.

Illouz, E. (2018). Soğuk Yakınlıklar Duygusal Kapitalizmin Şekillenmesi. (Ö. Çağlar Aksoy, Çev.) İstanbul: Illetişim Yayınları.

Klein, N. (2010). Şok Doktrini Felaket Kapitalizminin Yükselişi. (S. Özgül, Çev.) İstanbul: Agora Kitaplığı. 


\section{Byung-Chul Han \\ Psikopolitika}

NEOLIBERALIZM

VE YENI IKTIDAR TEKNIKLERI

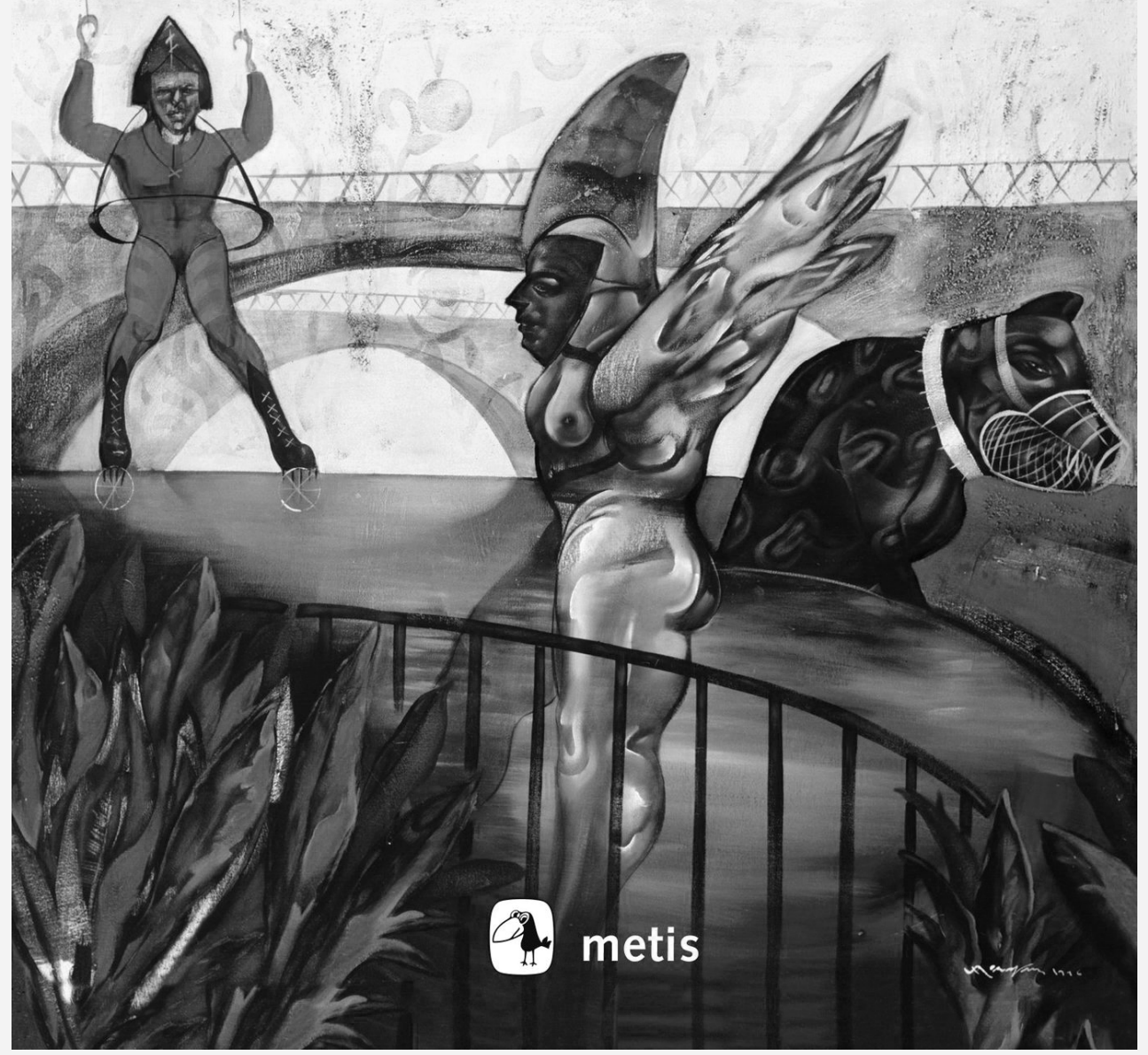

